\title{
Inda mbu, nambu or ine ti pu? Acquiring complex structures in Cypriot Greek
}

Natalia Pavlou

Department of English Studies, University of Cyprus, Cyprus

https://doi.org/10.36505/ExLing-2010/03/0036/000156

\begin{abstract}
The current study investigates the hypothesis that certain Cypriot Greek (CG) whphrases show similar paths of acquisition with cleft sentences based on syntactic complexity. That is, wh-phrases of the inda ( $m b u)$-type in CG can be decomposed in an abstract way as clefts, giving ine ti pu 'what is it that'. Targeting a comparison between these two structures, wh-questions with inda ( $m b u)$ along with subject- and object-clefts were included in a production elicitation experiment given to children aged 2;7-6;4. The preliminary results raise several issues ranging from syntactic complexities and movement difficulties in the two structures to sociolinguistic factors and implications for the possible diglossic situation in the Greek Cypriot community.
\end{abstract}

Key words: acquisition, diglossia, clefts, $w h$-questions

\section{Why clefts?}

Several issues in CG have been explored through the syntactic and pragmatic environment of clefts, which are widely used by Greek Cypriot speakers. Fotiou (2009) gives a first insight to the pragmatic role of the clefts and discusses the notion of focus and its different interpretation in CG clefts. With regard to wh-questions, Grohmann et al. (2006) suggest the 'embu-strategy' for the Cypriot-specific element $e m b u$, which is analyzed by them as a cleft: $e n(m) p u$ '(it) is that'.

More generally, a cleft-strategy is assumed in this study to be the underlying form of inda ( $m b u)$-questions in CG, which are restricted to $w h$-objects, true adjuncts, and $\mathrm{D}$ (iscourse)-linked $w h$-phrases (1). It should be noted that $m b u$ is assumed to be a variant of embu and appears in contexts where embu is not allowed (Grohmann et al. 2006, Pavlou 2010), and inda 'what' (excluded from the experiment because it is marginally accepted and used in Cyprus) emerged from an interrogative pronoun.

(1) a. Inda mbu vasta o andras?
what hold-3SG the man-NOM
$\begin{array}{lll}\text { b. Inda mbu fonazi } & \text { o andras? } \\ \text { why } & \text { shout-3SG } & \text { the man-NOM } \\ \text { c. Inda klei } & \text { o } & \text { andras? } \\ \text { why cry-3SG } & \text { the } & \text { man-NOM }\end{array}$

ExLing 2010: Proceedings of 3rd Tutorial and Research Workshop on Experimental Linguistics, 25-27 August, Athens, Greece 
d. Inda vivlio $\theta$ kiavazi o andras?

which book read-3SG the man-NOM

The observable decomposition of inda ( $m b u$ ) as ine ti pu (or ti ine pu) 'what is (it) that' is expected to have some effects on the 'special' acquisition of the CG clefts, $w h$-phrases and questions, and consequently their allomorphs (Pavlou 2010).

\section{The Guess What Game (GWG)}

The GWG is designed to function as a production elicitation game for whquestions and clefts with the use of pictures. The children are introduced to the GWG and requested to ask two supposedly ignorant puppets some questions. Each picture has two subjects and two items, with only one subject performing an action with one item. While the child is asking questions, s/he and the puppets are involved in a competition game, where the one who gives the most correct answers gets a chick from a guarded coop. If the puppets give wrong answers to the child's questions, then the child is awarded with a chicken.

The six different structures are ranging from the 4 inda-questions, given in (1), subject- and object-clefts, and are all randomized in 6 blocks, with two trials in the warm-up session and 4 test sentences.

The subjects were taken from kindergartens in the urban area of Limassol, after teacher and parental consent. Both parents of all children tested were Greek Cypriot. The children did not have any other learning difficulties or language disorders characteristics according to their teachers.

\section{Results}

Concentrating more on the type of the responses, the main results of this study will be presented here in three groups, the first dealing with whquestions and the issue of diglossia in Cyprus. The relevance of this linguistic situation in Cyprus played a role to the lexical choice of the whphrases used. As it appears in the results, the children replaced the target whphrases with the corresponding 'Standard Modern Greek (SMG)-like' whphrases. This could be an immediate effect of the low status of CG and the code-switch to the 'high' variety, which is SMG, as well as the perception of the researcher as a stranger to the children.

The production of clefts was characterised by the development of different strategies such as the replacement of both subject and object clefts with SVO declaratives (2a), normally expressing focus with the fronting of the subject in a focus-position. Other types of responses show lack of complete acquisition of clefts. Reduced clefts, as in (2b), were used for subject clefts 
and elliptical clefts (2c-d) for both cases. Focus in-situ (2e) was also met, especially for object clefts. In all cases, it is clear that children comprehend the pragmatic function of a cleft, which is focus, and develop different strategies to express it by avoiding the complexity involved by the clefts.

(2) a. O andras krata
the man-NOM hold-3SG car-ACC
b. En o andras
is-3SG the man-NOM
c. $\mathrm{O}$ andras pu krata aftokinitaki
the man-NOM that hold-3SG car-ACC
d.*Aftokinitaki pu krata o andras
car-ACC that hold-3SG the man-NOM
e. O andras krata to KOKKINO aftokinitaki
the man-NOM hold-3SG the RED car-ACC

Overall, the production of clefts started at the age group 4;0-5;0 with very low percentages. Interestingly, both subject- and object- clefts decrease in 5year-old children and then increase again in the 6-year-old age group.

Thirdly, common errors were widely found in D-linked wh-questions and divided in two categories. The percentages of errors in complex whquestions were relatively high in 4- and 5-year-old children. Errors which are marked as (-) pied-piping represent responses like (3a), whereas NPomission was used for sentences like (3b). In both of these, the target question was 'Which car is the man holding?' Complex wh-questions are generally perceived more difficult, hence assumed to be acquired late. However, there were systematic errors, showing the movement of the whword without the NP which was left in its base position. These errors hold the same percentages in 4- and 6-year-old children and appear less in 3-and 5 -year-old children. NP omission, and consequently inversion of referential to argumental $w h$-questions, similarly to Greek (Stavrakaki 2006), was very strong in 5-year-old children, while also appearing in 4- and 6-year-old children.
(3) a. \# Inda (or ti) krata aftokinitaki o andras? which hold-3SG car the man-NOM
b. \# Ti (or inda) krata o andras? which hold-3SG the man-NOM

A determining factor for explaining these errors was the calculation of $w h$ word alternation between CG and 'SMG-like' $w h$-words. The problematic 
responses in 2- and 3-year-olds appear low with CG 'which', whereas both types of errors are greater in number in 4-, 5-, and 6-year-old children with the use of the 'SMG-like' $w h$-phrases.

\section{Some First Thoughts}

The combination of different structures has given a 'report' character to this ongoing study by providing some first data for certain complex structures. The sociolinguistic factors affecting the results, as well as the syntactic complexities observed have set the need for further and more specific research in these topics. Greek Cypriot children perform differently in complex wh-questions from Greek children (Stavrakaki 2006), that is, from (mainland) Greece speaking SMG, and the $w h$-word alternations between CG and SMG observed show that the use of SMG in pre-school years may start earlier than assumed in kindergartens.

The Cyprus Acquisition Team (CAT) is currently investigating the exact time and effects of SMG instruction and use in both the pre-school and school years through specific structures in an attempt to identify the preschool variety used by Greek Cypriot children. Presumably, young speakers develop their linguistic awareness for the difference between CG and SMG very early and thus can make decisions for it, which in this case appeared as non-CG lexical choices for the aforementioned wh-phrases. However, first results indicate that conscious decisions may not be the only or even most relevant factor for CG-SMG alternations, but the overall use of SMG can affect certain structures and their acquisition.

\section{References}

Fotiou, C. 2009 Focusing strategies in Cypriot Greek. In K.K. Grohmann and P. Panagiotidis (eds.), Selected Papers from the 2006 Cyprus Syntaxfest, 63-91. Newcastle upon Tyne: Cambridge Scholars Publishing.

Grohmann, K.K., Panagiotidis, P., Tsiplakou, S. 2006. Properties of wh-question formation in Cypriot Greek. In M. Janse, B.D. Joseph, A. Ralli (eds.), Proc. 2nd Intern. Conference on Modern Greek Dialects and Linguistic Theory (Mytilene, Greece: 30 September-3 October 2004). Patras: University of Patras, 83-98.

Papadopoulou, E. In progress. Acquisition of wh-questions: Evidence from Cypriot Greek. University of Essex, Colchester: PhD dissertation.

Pavlou, N. 2010. MBU! On wh-objects and true adjuncts of Cypriot Greek. In a. Ralli, B.D. Joseph, M. Janse, A. Karasimos (eds.), Proc. 4th Modern Greek Dialects and Linguistic Theory Conference. University of Patras, Department of Philology, Linguistics Division, 155-178. (electronic publication)

Stavrakaki, S. 2006. Developmental perspectives on specific language impairment: Evidence from the production of $w h$-questions by Greek SLI children over time, Advances in Speech-Language Pathology 8, 384-396. 